\title{
NARRATIVAS DE VIDA DE ESTUDANTES UNIVERSITÁRIOS: UMA ANÁLISE DO SENTIDO EXISTENCIAL POR MEIO DA AUTOBIOGRAFIA
}

\author{
Life Narratives of university students: an analysis of existential meaning through the process of \\ Autobiography
}
Narraciones de vida de estudiantes universitarios: análisis del sentido existencial por medio de la Autobiografía

Amanda Karla Diniz Liberato Chaves

Thiago Antonio Avellar de Aguino

\begin{abstract}
Resumo: A autobiografia é um recurso utilizado na prática da Logoterapia e análise existencial que tem por finalidade clarificar sentidos na vida por meio de histórias de vidas. Assim, a partir dos fundamentos antropológicos propostos por Viktor Frankl, a presente pesquisa teve como objetivo apreender valores existenciais, e identificar núcleos de sentidos latentes em narrativas de vida de jovens universitários. Para tanto, contou com a participação de quatro estudantes universitários, de ambos os sexos, com média de idade de 23 anos. As autobiografias foram submetidas individualmente a uma análise de similitude com o auxílio do software Iramuteq, o que permitiu identificar núcleos de sentidos. Os resultados foram discutidos à luz da Logoterapia e Análise Existencial.
\end{abstract}

Palavras chave: Autobiografia; Logoterapia; Sentido.

\begin{abstract}
Autobiography is a resource used in clinical practice of Logotherapy and existential analysis with the purpose of clarifying meanings in life through histories of life. Therefore, based on Viktor Frankl's anthropological foundations, this research aims to apprehend existential values as well as to identify nuclei of meanings that are latent in the narratives of life of university students. For this purpose, this study had the participation of four undergraduate students, of both genders, with a 23 year old average age. The autobiographies were submitted to an individual analysis of similitude that counted with the help of software named Iramuteq, which allowed the identification of the so called nuclei of meanings. The results were discussed through the light of logotherapy and existential analysis.
\end{abstract}

Keywords: Autobiography; Logotherapy; Meaning.

\begin{abstract}
Resumen: La autobiografía es un recurso utilizado en la práctica de la Logoterapia y análisis existencial, que tiene por finalidad clarificar los sentidos en la vida por medio de historias de vida. Así, a partir de los fundamentos antropológicos propuestos por Viktor Frankl, la presente investigación tuvo como objetivo aprehender los valores existenciales e identificar los núcleos de sentidos latentes en narraciones de vida de jóvenes universitarios. Para ese propósito, contó con la participación de cuatro estudiantes universitarios, de ambos sexos, com una media de edad de 23 años. Las autobiografías fueron sometidas individualmente a un análisis de similitud con la ayuda del software Iramuteq, lo que permitió identificar núcleos de sentidos. Los resultados fueron discutidos desde el punto de vista de la logoterapia y análisis existencial.
\end{abstract}

Palavras clave: Autobiografía; Logoterapia; Sentido.

\section{Introdução}

A história de vida e os relatos autobiográficos podem ser encontrados desde a antiguidade com a publicação da obra Confissões de Santo Agostinho (398/1981), entretanto, como metodologia de pesquisa, atribui-se a Thomas e Zananiecki (1927) em sua clássica obra The Polish Peasant in Europe and America. Nesta mesma direção, Runyan (1978) propõe o estudo do curso de vida como uma sequência de interações entre pessoa e situação desde o nascimento até a morte, compreendendo, dessa forma, que as pessoas seriam influenciadas por essas sequências de eventos. Já Becker (1994) assevera que "o autor autobiográfico se propõe a explicar sua vida para nós, se comprometendo, assim, com a manutenção de uma estreita conexão entre a história que conta e aquilo que uma investigação objetiva poderia descobrir" (p. 102), ademais alerta o autor que toda história de vida é sempre parcial, pois o autor sempre seleciona aquilo que narra.

A autobiografia pode ser compreendida como uma escrita acerca da própria existência e se constitui um recurso útil no âmbito da Psicologia, seja no seu aspecto de pesquisa, seja na esfera da psicoterapia. Bruzzone $(2011$; 2018) afirma que a autobiografia é um elemento facilitador para o autoconhecimento que pode promover tanto mudanças existenciais quanto permitir ressignificar acontecimentos passados, por meio de posturas e ações perante o vivido. Nesta mesma acepção, Abrahão (2006) considera que a narrativa autobiográfica pode 
ressignificar acontecimentos passados, além de desvelar o sentido da vida do narrador.

Por sua vez, a Psicobiografia foi o campo que mais se ocupou com personalidades históricas procurando compreender suas vidas à luz de uma teoria psicológica, como foi o caso do estudo sobre Leonardo da Vinci realizado por Sigmund Freud (Runyan, 1988). Entretanto, teorias humanistas e existenciais se detêm em análises de histórias de vida de pessoas comuns, por esse motivo, para a compreensão de autobiografias, o presente artigo partiu da análise existencial frakliana a qual representa uma perspectiva antropológica de pesquisa que se propõe a clarificar o sentido da existência na história de vida (Frankl, 1989).

Para Frankl (1989) “(...) o simples fato de que o homem comum sinta necessidade de uma coisa como o cinema e o teatro, demonstra já o caráter de sentido do histórico" (p. 111-112). Nessa perspectiva de historicidade, a existência humana pode ser comparada à atividade do escultor, que extrai uma forma das possibilidades de uma pedra inicialmente informe, levando em consideração que há um tempo para o seu término. O que caracteriza a existência é o caráter de escolha entre as múltiplas possibilidades de ser. Desta forma, o ser humano está em uma contínua relação dialética entre realidade e possibilidade, ou seja, entre "ser" e "poder-ser" que se constituem na temporalidade uma história de vida pessoal (Frankl, 1989).

Nessa perspectiva, o ser humano se constitui como um ente livre, pois é um ser que decide, e, por conseguinte, responsável, tendo em conta que responde a cada momento qual possibilidade deixará fluir para o passado. Nesse ato de escolher, a vontade de sentido joga um papel muito importante, já que a possibilidade precisa conter algo valoroso para o ser (Frankl, 2011). Assim, conclui o autor que "ser homem" significa ser consciente e responsável, ou seja, consciente das possibilidades de sentido e responsável por efetiválas (Frankl, 2012). Nessa dinâmica da existência o ser humano é atraído pelos valores, posto que é um ser que sempre decide o seu vir-a-ser (Frankl, 2019).

De forma geral, para Frankl (2011), a pessoa se explica na medida em que se desenvolve no decurso da vida em um campo de tensão entre o ser e o dever-ser. "A vida consiste na tensão indispensável entre o que é e o que deveria ser. Pois o homem não se destina a ser, mas vir a ser" (Frankl, 2019, p. 273). Frankl (2019) alerta que apenas é possível fazer uma análise orientada para a existência, tendo em conta que a existência não é passível de síntese. Assim, o ser humano é histórico e orientado para o futuro (Frankl, 1989a). "Sem um ponto fixo no futuro, não consegue o homem propriamente existir. É em ordem do futuro que normalmente todo o seu presente é configurado, orientando-se para ele como a limalha de ferro se orienta para um polo magnético" (Frankl, 1989, p. 143).
Além disso, o passado seria a dimensão mais segura da existência, pois estaria irremediavelmente perene enquanto o futuro estaria apenas como possibilidades de ser. Nessa perspectiva o ser humano "lê na vida" (Frankl, 2012) por meio de sua autocompreensão ontológica. Em última análise, a biografia é a explicação temporal da pessoa, ou seja, a sua manifestação e expressão como um ser-nomundo (Frankl, 2012). O autor aventa que por meio da ação o ser humano transforma as possibilidades em realidades, dessa forma, além de agir de acordo com o que é, o ser humano também se transforma por meio de sua própria escolha e ação no mundo (Frankl, 1989).

Para Frankl (2011) “(...) a vida é uma Zeitgestalt, uma Gestalt de tempo, e que, como tal, ela tende a formar um todo inteligível apenas quando seu curso for completado" (p. 57). Isto posto, o ser humano não se constitui no vácuo, ele chega a ser o que é a partir da realização de sentidos (logos) e de valores (o ethos e o eros). Frankl (1989; 2010) aponta três vias para configurar sentidos na existência: vivenciando algo ou alguém (valores vivenciais); criando algo para o mundo (valores criativos) e se posicionando perante um destino trágico (valores atitudinais), tornando-se digno do próprio sofrimento.

Pode-se compreender que a perspectiva dos valores vivenciais e criativos conduz a interpretação do ser humano como um ente aberto para o mundo. Por consequência, a estrutura existencial antropológica fundamental é a autotranscendência, ou seja, aquela constituição ontológica de abertura para o mundo que suspende todo ato de autocontemplação. Quanto mais humano, mais se transcende para uma obra criativa ou para a contemplação estética, para um ser amado ou se dedicar a uma causa (Frankl, 2011, 2012). Já o valor atitudinal requer a emergência de outra característica antropológica: o autodistanciamento, que se manifesta por meio do heroísmo e do humor (Frankl, 2011).

Segundo o autor em tela, a vida demanda perguntas e, por outro lado, o ser humano valora o que tem mais sentido ou o que é destituído de significado por meio da consciência intuitiva (Gewissen). Conforme pensa o autor em foco, “(...) na percepção de sentido, trata-se da descoberta de uma possibilidade diante do pano de fundo da realidade" (Frankl, 1990, p. 45). Em outras palavras, existir significa responder à vida, conferindo forma e sentido à existência (Frankl, 1990).

De certa forma, a visão de Frankl está em consonância com o pensamento de Kluckhohn e Murray (1953) quando afirmam que "todo homem é em certos aspectos (a) como todos os outros homens, (b) como alguns outros homens, (c) como nenhum outro homem" (p. 53). Com o desdobramento de sua historicidade, o ser se configura no mundo como único e irrepetível. Com o intuito de apreender as idiossincrasias das histórias de vida por meio 
da compreensão antropológica de Frankl (2019), Lukas (1998) propõe a metodologia denominada autobiografia dirigida como a via régia para clarificar a compreensão ontológica do passado, do presente e do futuro. Esta metodologia também foi utilizada por autores como Ovejas, Morelli, Moretti, Peña e Eterovic (2013) e Oliveira (2015) em diversos contextos terapêuticos.

Apesar de sua importância para a promoção e clarificação da busca de sentido no campo da psicoterapia, pesquisas acerca das escritas autobiográficas ainda carecem de um critério mais rigoroso para apreender significados latentes provenientes das produções textuais. Segundo Camargo e Justo (2013), a análise textual é adequada para o estudo acerca de pensamentos, crenças e opiniões, quiçá possa ser útil para analisar as narrativas de vida. Ademais, o presente tema se torna relevante na medida em que pode iluminar o caráter de historicidade da existência humana para fins de descoberta de valores e sentidos na existência. Tendo em conta as considerações supracitadas, a presente pesquisa teve como objetivo apreender valores existenciais e identificar núcleos de sentidos latentes em narrativas de vida de jovens universitários.

\section{Trajetória Metodológica}

\section{Procedimentos éticos}

A pesquisa foi submetida ao Comitê de Ética e aprovada por este conforme Certificado de Apresentação para Apreciação Ética (CAAE) número 88767118.2.0000.5188, e seguiu todas as recomendações éticas em pesquisa com seres humanos. Os participantes assinaram um Termo de Consentimento Livre e Esclarecido (TCLE). As condições para participar do estudo foram: ter mais de dezoito anos, ser universitário e concordar em escrever a sua autobiografia. Para preservar o anonimato dos participantes, foi atribuído um pseudônimo com nomes de pedras preciosas: Ágata, Ametista, Topázio e Quartzo.

\section{Participantes}

Participaram do estudo quatro pessoas, sendo dois homens e duas mulheres, com média de idade de 23 anos. Todos os participantes eram estudantes universitários, solteiros e, com exceção de uma participante, todos os outros apresentavam um relacionamento estável (namoro).

\section{Procedimento para coleta dos dados autobiográficos}

As autobiografias foram produzidas durante a ministração de uma disciplina, no curso de psicologia de uma universidade pública, da região do Nordeste do Brasil. Inicialmente, com o intuito de descrever os participantes, foi solicitado que informassem os seguintes dados sociodemográficos: sexo, idade, escolaridade, estado civil e religião. Em seguida, foi solicitado individualmente uma produção textual de uma autobiografia conforme a metodologia proposta por Lukas (1998) que considera três perspectivas: a visão retrospectiva (passado), o momento presente e a percepção prospectiva (futuro). Na primeira parte os participantes discorreram sobre os pais, o período pré-escolar, o período escolar, a maturidade até o momento presente. Em seguida escreveram sobre o momento presente, o futuro próximo, futuro distante, a morte e, por fim, foram convidados a refletirem sobre as pegadas que deixarão no mundo após a morte.

As autobiografias foram realizadas originalmente no Word para windows, dividido em duas colunas: $\mathrm{Na}$ coluna do lado esquerdo, foram descritos os fatos cronológicos, enquanto o lado direito o participante descreveu suas posturas, pensamentos e sentimentos relacionados aos acontecimentos da sua história de vida. Esta produção textual constituiu o corpus da análise.

\section{Procedimento para análise da autobiografia}

Após a construção textual das autobiografias dirigidas, que são os corpus, foram transferidos, em sua íntegra, para o bloco de notas do Windows e em seguida procedeu-se a uma análise de similitude por meio do software Iramuteq, Interface de $R$ pour les Analyses Multidimensionnelles de Textes et de Questionnaires (Ratinaud, 2009). Esta análise identifica conexidade entre palavras contidas em um corpus por meio das suas ocorrências. Este procedimento permitiu identificar as vinculações entre palavras do corpus textual, possibilitando, desta maneira, identificar a estrutura do corpus textual e por consequência os núcleos de sentidos (Ratinaud \& Marchand, 2012).

\section{Resultados e discussão}

Análise existencial da autobiografia de Ágata

Ágata é uma universitária do sexo feminino, tem 24 anos de idade e cursava o último ano de sua graduação no curso superior. Participava de uma comunidade católica e mantinha um relacionamento estável com seu namorado. Foi constatado que as palavras mais repetidas ao longo da autobiografia de Ágata foram: "não”, "sentir”, "estar" e "muito”. Com a ajuda da análise de similitude, foi possível encontrar sete núcleos de sentido, que dizem respeito aos aspectos vivenciais, profissionais - conclusão do curso, religiosos e familiares, estado atual, passado e autopercepção. Os núcleos e suas ramificações podem ser observados na árvore de coocorrência na Figura 1. 


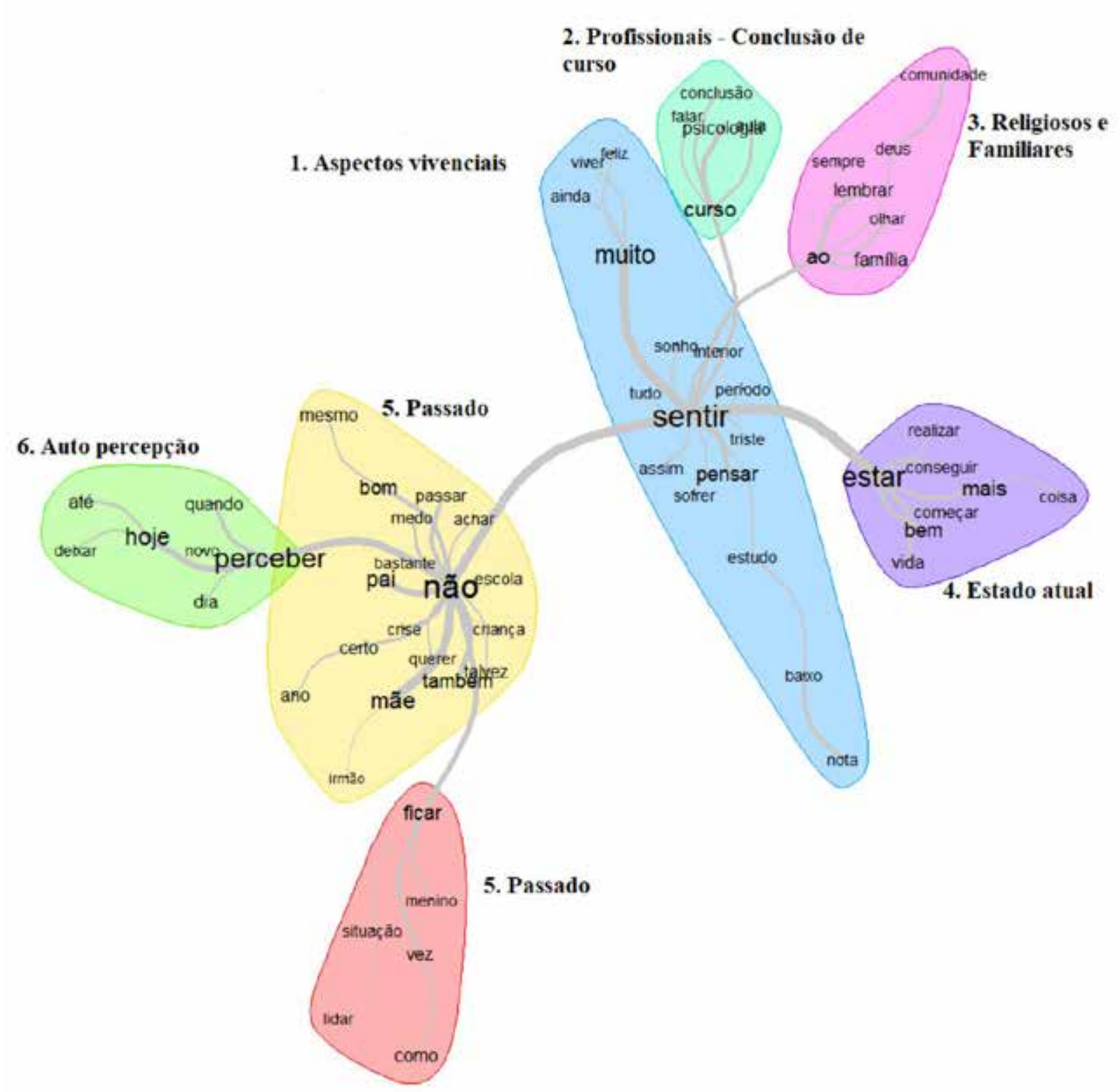

Figura 1. Árvore de coocorrência da autobiografia de Ágata.

\section{Aspectos vivenciais}

Os aspectos vivenciais dizem respeito tanto aos seus valores quanto ao seu estado afetivo no momento presente. A palavra central foi "sentir" que reuniu os termos pensar, muito, tudo, período, interior, sonho, feliz, viver, ainda, triste, assim, sofrer, estudo, baixo e nota.

Os trechos a seguir mostram que os aspectos vivenciais de Ágata estão relacionados com a família e com os estudos, o que demonstra a sua percepção acerca de sua situação existencial:

Depois a luta interior para se manter no mesmo nível do pessoal que estava em ritmo com os estudos a um tempinho, fora a sensação de me sentir um corpo estranho, deslocada no meio social...

Noivar e casar: Sinto que será um sonho se realizando... Sei que estou bem ansiosa para que isso se realize rápido, porém, carregada de preocupações diante das responsabilidades (...) Me sinto triste, um pouco desamparada da real estrutura familiar que penso, que sonho. Penso que agiram com imaturidade.

Evidencia-se aqui o estado psíquico de Ágata em relação a sua família nuclear. Entretanto, nesse mesmo núcleo novas possibilidades se desdobram na perspectiva de um futuro valor vivencial, sobretudo por meio do amor, na busca de um ideal a ser realizado na relação com um tu.

\section{Profissionais: Conclusão de Curso}

Este núcleo de sentido foi composto pelas seguintes palavras: curso, psicologia, falar e conclusão. O futuro pode ser uma fonte de ansiedade, mas Ágata intenciona prosseguir, conforme explicita a seguir: 
Sinto que é algo que devo fazer, mesmo diante das incertezas. Penso que tem sido desafiador encarar essa etapa, por vários motivos, cansaço, falta de conviç̧ão sobre a profissão, medo do mercado de trabalho... Às vezes penso que não me conheço ou que não sou determinada o bastante. Porém, como pontuei, independente das circunstâncias e dos questionamentos, é meta concluir.

Na etapa de conclusão do curso... Sinto que preciso me focar para realmente terminar o curso e que a conclusáa seja com êxito. A angústia/ a ansiedade para entrar no mercado já vai "batendo a porta", será que conseguirei? Mas, estou caminhando (...)

Apesar da angústia do término do curso, a vida de Ágata pode ser compreendida como uma tarefa que neste momento exige uma realização, o que provoca uma tensão entre ser e dever-se, este último pode ser compreendido como a conclusão do seu curso. Ademais ela apresenta uma postura apesar das circunstâncias, pois afirma possuir um sentido e uma meta a concluir.

\section{Família e Religião}

Este núcleo de sentido diz respeito à família e a religião, pois se encontram as palavras: Deus, família comunidade, olhar, lembrar e sempre. Uma marca em sua historicidade decorrente da separação dos pais, principalmente na sua infância e adolescência. Apesar desse fato, também é notório o desejo de constituir sua própria família, como relata na sequência:

Sinto que boa parte da minha infância e adolescência foi realizar esse sonho, meu, mas eu sentia que também deles, mas que nunca entendi o porquê não voltaram já que diziam se amar... Sofri muito, mas amadureci. Hoje eu sonho em construir a minha família, buscando a real fidelidade.

O relato acima identifica o sofrimento com a maturidade, o que coincide com a conclusão de Frankl (2019): "situações extremas levam o homem a alçar tanto a liberdade interior quanto a maturidade" (p. 302). Para Frankl (2011) o ser humano busca, em última análise, um motivo para ser feliz, neste caso específico seria a constituição de uma família, baseada no amor e na confiança/fidelidade, dois elementos vivenciais e fundantes da existência. Já com relação à comunidade religiosa, da qual faz parte, é notória a sua relevância para a sua biografia, como pode-se perceber nos trechos a seguir:

Há 8 anos participo de uma comunidade religiosa... Abracei a vida consagrada há quase três... Percebo que a comunidade me ajudou a me encontrar em mim... A ser mais humana e acima de tudo, a estar mais próxima de Deus, sem alienação, mas com maturidade. Me sinto pertença deste carisma, desta vocação. Vejo que vivi um processo e tenho muito o que ainda percorrer, desde quando cheguei até aqui, no meu hoje...

Foi desafiador... No início foi muito difícil, pois eu ainda morava na comunidade e conciliar estudos e vida comunitária nunca foi fácil, mas percebi que Deus me agraciou muito.

Para Frankl (1990) a vida se manifesta como uma incumbência, já a pessoa religiosa além de vivenciá-la como tarefa, se relaciona também com aquele que colocou a tarefa (o supra Ser). Frankl (1989) compreende que o sentido se concretiza na comunidade, pois o ser humano é um ente aberto para o mundo. Sendo um ente incompleto, é apenas na comunidade que a existência se configura com um sentido, já que na massa o ser humano é despersonalizado (Frankl, 1989). Ademais, o seguimento de texto de Ágata, sugere que esta abertura ocorre tanto os membros do seu grupo religioso quanto para um Tu transcendente (Deus). Além disso, a singularidade de cada pessoa se manifesta em sua transcendência para à comunidade humana (Frankl, 1990). Desta feita, para Frankl (1989), “(...) o sentido da personalidade humana, é sempre orientado e referido à comunidade" (p. 114). A vivência comunitária e religiosa permitiu, por efeito, uma reintegração de si mesma, assim como a ajudou no seu processo de crescimento interior conforme sugerem a autocompreensão ontológica de Ágata.

Na autobiografia, Ágata afirma descobrir um novo sentido para a sua vida que a fez se dirigir para o futuro:

Comecei a namorar a alguns meses... Estou bem feliz.... Ser amada é algo muito bom. Além do que é um passo para uma futura concretização de um sonho daquilo que não tive como queria ao certo.... Uma família (...)

A felicidade pode ser compreendida como um efeito adicional da descoberta e realização de um sentido (Frankl, 2011). O amor, como fenômeno genuinamente humano, pode conferir sentido à vida e é compreendido como "a única maneira de captar outro ser humano no íntimo de sua personalidade" (Frankl, 2017, p. 136). Assim, no caso de Ágata também é uma via para o encontro de novos sentidos, como o de constituir uma família.

\section{Estado atual}

Este núcleo de sentido se refere ao estado psíquico do momento presente, vinculado ao término do curso superior. O verbo "estar" se associa 
com as seguintes palavras: realizar, conseguir, mais, coisa, começar, bem e vida. Por um lado, Ágata expressa, em sua dimensão psíquica, o medo em relação a conclusão do seu curso, por outro, emerge a sua dimensão especificamente humana, como se pode ver nos seguintes trechos:

Estou com um pouco de medo de não conseguir vencer o que estou passando, porém também estou ansiosa, na expectativa de que eu volte a ter paz interior novamente.

Para Frankl (2012) as crises existenciais provocadas pelas dúvidas em relação ao sentido podem provocar a perda da confiança básica. Ao olhar para a sua situação existencial, encontra-se entre o medo e a expectativa de reencontrar a "paz interior”. Compreende-se que a "paz interior” é uma consequência de decisões em prol de um sentido e não deve ser um objeto de intencionalidade. Nesses casos, torna-se imperativo descobrir o sentido latente na situação para a superação de seu conflito.

\section{Passado}

Este núcleo diz respeito ao passado, pois emergiram palavras referentes a este período, tais como: não, escola, pai, mãe, criança, querer, talvez, também, crise, bastante, medo, passar, achar bom, mesmo, certo, ano e irmão. A logoterapia compreende que o passado é a dimensão mais segura do ser (Frankl, 2017a), entretanto, nesse momento da autobiografia, emerge uma interpretação negativa, relacionada a palavra "não", como se observa a seguir:

Primeira escola: Percebo que foi meu primeiro contato social em que me pedia estar longe dos meus pais... Tive medo. Mas, hoje não me pergunto, se não houve apego demais entre mim e meus pais a ponto de eu não conseguir ficar brincando com outras crianças...

Sinto que isso não foi muito bom para ambas. Criou uma dependência não sadia, um conflito no que seria a verdadeira função de cada uma, uma é filha e a outra é mãe, uma era criança e a outra, adulta... Sinto que por parte da minha mãe, ainda a resquícios de um 'Cordão umbilical' que não se permitiu, que teve medo de ser cortado.

Segundo a logoterapia, embora o passado possa repercutir no presente, ele não determina completamente o ser humano (Frankl, 2012). A sua ansiedade pode ser decorrente do seu ser-assim e de suas vivências passadas (facticidade), mas sempre há uma possibilidade de uma guinada existencial a partir das possibilidades que se encontram na sua área de liberdade.

\section{Autopercepção}

Por fim, este núcleo diz respeito a autopercepção da participante sobre as suas vivências, ou seja, como ela se posiciona perante o seu destino, reuniu as palavras: perceber, dia, novo, quando, hoje até, deixar. Ágata percebe alguns valores que foram perdidos, pois não existem mais como potencialidade, como, por exemplo, a convivência com seu pai, decorrente de uma separação:

\section{Ao lembrar, tenho vontade de chorar... Percebo o quanto foi muito difícil para mim não ter tido a presença física na convivência diária, do meu pai... Vejo o quanto isso era e ainda é importante para mim.}

Entretanto, a vida sempre proporciona novos sentidos e o ser humano precisa sempre responder, como se pode constatar na frase a seguir:

Percebo um coração preocupado com o próximo, mas que deixou a emoção falar bem mais alto... Hoje, eu tentaria pensar em outra possibilidade de ajudar minha amiga.

Neste último núcleo existencial, percebe-se um movimento de encontrar sentido nas vivências passadas, diante de situações difíceis. Além disso, a autopercepção de Ágata faz com que ela se veja como uma pessoa autotranscendente, ou seja, uma pessoa que não está voltada apenas para si, mas também para alguém. Além disso, Ágata se autocompreende como uma pessoa idealista, como a própria se define quando diz: "Percebo que a característica sonhadora vem desde cedo em mim”.

\section{Análise existencial da autobiografia de Ametista}

Ametista é uma estudante universitária do sexo feminino, tem 21 anos de idade e é solteira. Embora tenha se constituido em uma cultura religiosa católica, ao escrever a sua autobiografia, ela autodenomina-se como sem religião.

As palavras mais frequentes na narrativa da autobiografia de Ametista foram: pessoa, vida, ano, querer, sentir e saber. A palavra "pessoa" refere-se a quem Ametista é, bem como as pessoas que ela conheceu durante a sua história de vida. O termo "vida" refere-se a sua historicidade constituída por suas vivências, enquanto a palavra "ano" faz referência à temporalidade do vivido. A palavra “querer" reflete a vontade de Ametista, tanto aquilo que já ocorreu quanto o que ainda almeja realizar, e por "sentir" desvela os seus sentimentos diante dos fatos cronológicos. Por fim, a palavra "saber" retratou dúvidas e certezas acerca da sua própria existência.

Com a análise de similitude foi encontrado sete núcleos de sentido nomeados de: o vivido, 
historicidade, núcleo familiar, valor vivencial, dimensão racional, vontade e futuro. Os núcleos e suas ramificações podem ser observados na árvore de coocorrência na Figura 2.

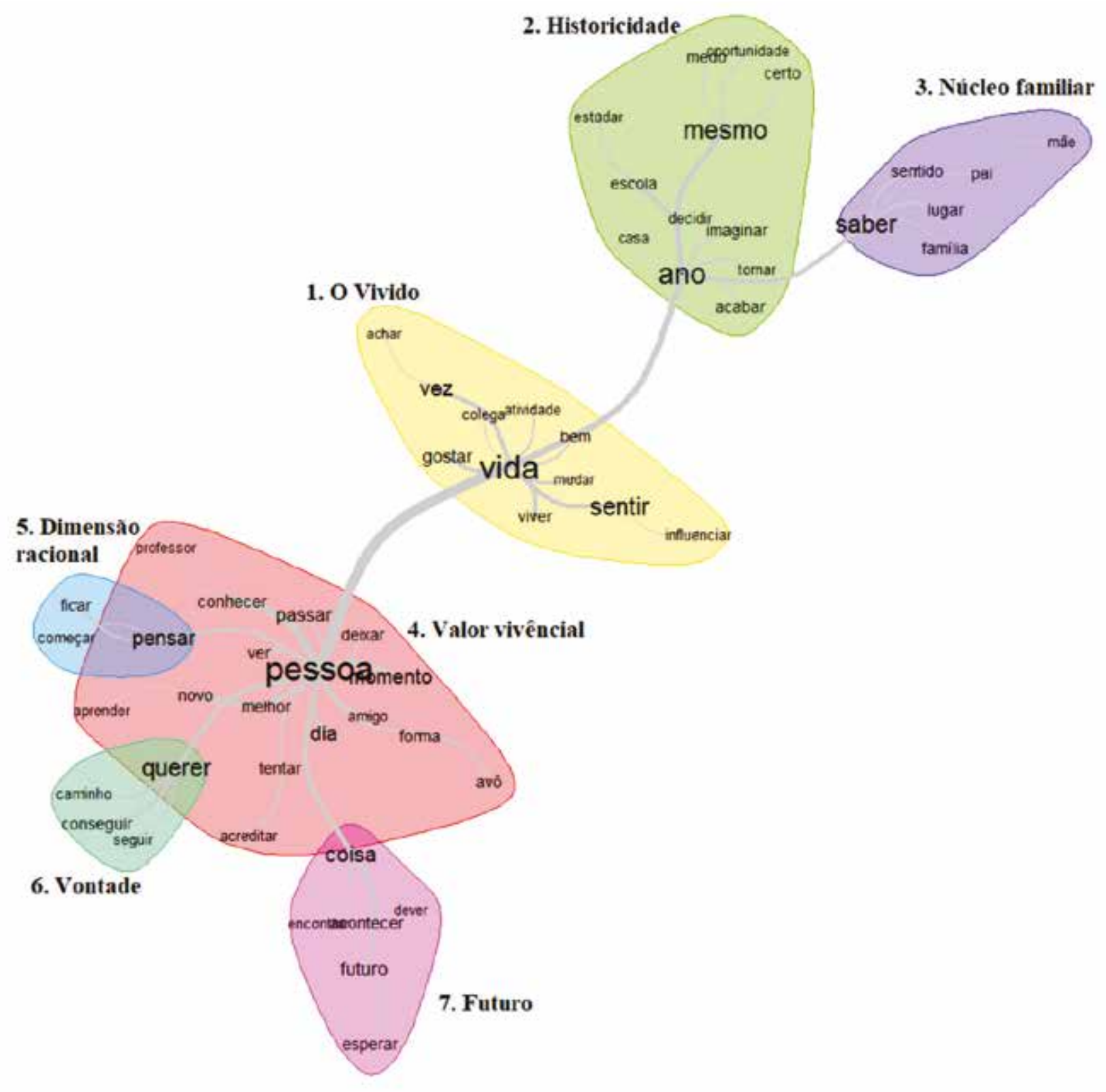

Figura 2. Árvore de coocorrência da autobiografia de Ametista.

\section{0 vivido}

Este núcleo refere-se ao vivido e apresenta um questionamento sobre a forma de estar no mundo, como pode ser constatado no seguimento:

Eu gostaria de aproveitar mais o que a vida me oferece... No mundo tecnológico em que vivemos hoje, olhar para baixo, para a tela do celular, é bem mais fácil do que olhar em frente e enxergar de verdade.

A vivência de Ametista aponta para um questionamento do modo de ser inautêntico, que escapa da verdadeira demanda da existência. Frankl
(1990) alerta para a fugacidade das potencialidades, entretanto, quando o ser humano realiza uma possibilidade, a preserva da sua transitoriedade. Ademais, pode-se inferir uma vontade de ser autentica quando Ametista ela se refere ao olhar em frente e enxergar de verdade, ou seja, demonstra o anseio de uma mudança de postura, a qual possa aproveitar o sentido que a vida lhe oferece a cada momento.

\section{Historicidade}

Este núcleo de sentido foi composto pelas palavras: ano, mesmo, decidir, casa, escola, estudar, imaginar, tomar, acabar, mesmo, medo, 
oportunidade, certo. Como exemplo destaca-se o seguinte recorte da autobiografia.

\begin{abstract}
Ainda sinto que não tenho a tendência de sabotar minhas próprias conquistas e oportunidades pelo medo de que algo dê errado e eu acabe me decepcionando e me frustrando depois, mas venho tentando trabalhar esse aspecto em mim mesma, tenho buscado acreditar mais em minhas potencialidades e a arriscar mais com relação ao desconhecido e ao novo.
\end{abstract}

O ser humano sempre se posiciona perante as condições externas ou internas (Frankl, 2019). Segundo Frankl (2012) ex-sistir significa emergir, ou seja, estar diante de si, como que sugere no discurso acima destacado. Na perspectiva de Frankl (1990), a vida se constitui como um contínuo ato de fazer escolhas, onde a vida questiona e o ser humano responde. Neste caso, o segmento de texto manifesta não apenas o medo de fazer escolhas, mas o temor de perder as oportunidades que são transitórias, o que possivelmente a faz superar o tremor do desconhecido; emerge, assim, a sua vontade de sentido, por meio de sua crença em suas potencialidades.

\section{Valor vivencial}

Este núcleo de sentido foi composto pelas palavras: pessoa, momento, deixar, passar, conhecer, professor, ver, melhor, novo, aprender, tentar, acreditar, dia, amigo, forma, avô. Ele indica uma das formas de estar no mundo de Ametista que desvela o seu vivido.

Nesse momento, comecei a pensar em meu avô, uma pessoa que eu queria ter visto, conhecido, conversado, rido com. Eu estava procurando o meu avô nas nuvens, porque na vida real eu nunca ia conseguir encontrá-lo novamente.

No exemplo dado, Ametista pensa em seu avô que mesmo ausente, está presente em sua memória. Tal fato assemelha-se a experiência de Frankl (2017) no campo de concentração, onde este contempla a imagem espiritual de sua esposa dentro de si, chegando a conclusão de que o amor, um dos meios de vivenciar algo ou alguém, não está relacionado unicamente com a existência física, mas na essência do ente querido, ou seja, no seu "ter sido".

\section{Vontade}

Este núcleo é composto pelas palavras querer, caminho, conseguir e seguir. Como exemplo, apresenta-se o seguinte trecho:

Sigo meu caminho, refletindo sobre aquilo que quero mudar, aquilo que quero fazer, como quero usar meu tempo, como posso realizar algo de valor e significativo tanto para mim quanto para aqueles que eu consiga tocar ao longo de minha existência.

A vontade requer um fundamento, dessa forma, para Frankl (1989), a vontade é despertada por valores e sentidos, no caso de Ametista, desperta a sua vontade de sentido na medida em que reflete acerca do que deseja fazer na sua existência. Nesse caso, a busca por algo valoroso e significativo demonstra um interesse por algo no mundo que proporcione o fenômeno da autotranscendência.

\section{Futuro}

Este núcleo de sentido comporta as palavras: coisa, dever, encontrar, acontecer, futuro, esperar. Como exemplo, destaca-se:

(...) Mesmo o futuro permanecendo incerto, o caminho que escolhi fará sentido para mim.

Em contraposição ao "fatalismo", Frankl (2017) propõe em sua teoria um "ativismo do futuro", ou seja, fazer com que o ser humano seja ativo e responsável pelas escolhas, entre as inúmeras possibilidades que guarda o futuro, pois são estas que irão entrar para a realidade do passado. A partir da análise da autobiografia de Ametista, pôde-se perceber que ela atribui grande importância para o futuro. De fato, é no futuro que estão contidas todas as possibilidades de ser e por meio de suas escolhas, pode-se ocorrer uma mudança em sua constituição ontológica. Ametista mostra que "fazer mudança” e realizar sentidos é a sua prioridade, aplacando assim o desespero e a desesperança.

\section{Dimensão Racional}

Este núcleo abarca as seguintes palavras: pensar, ficar, começar. Retrata a forma como Ametista age frente a diversas situações. Este núcleo está relacionado com os acontecimentos do passado e suas influências na vida de Ametista, o porquê de sua racionalidade. No entanto, como já foi dito na análise dos núcleos anteriores, no momento em que escreve sua biografia, Ametista revela o desejo de se transformar no futuro, desta forma, ela mostra mais uma vez o ativismo do futuro, além de mostrar a possibilidade de realização de valores atitudinais, em que, mesmo diante de um destino imutável ou frente a uma situação imutável o ser pode mudar sua atitude perante os condicionamentos (Frankl, 2017a). Como exemplo desse núcleo destaca-se:

Demorei um bom tempo para conseguir me abrir para novas amizades, mas ainda assim mantinha distância, não queria ficar muito próxima de ninguém, minhas amizades anteriores haviam me ensinado que não se deve confiar facilmente nos outros.

Ademais, esse segmento de texto demonstra 
a sua capacidade de autodistanciamento ao refletir sobre a sua experiência passada e sua capacidade em reconhecer o valor da amizade em seu campo perceptivo, o que a levou a superar a sua desconfiança inicial em relação aos outros.

\section{Família}

Este núcleo é composto pelas seguintes palavras: saber, sentido, pai, mãe, lugar, família. Ametista explana sobre a sua família e sobre as influências que recebeu da mesma, as quais fazem parte da sua constituição como pessoa, como se constata neste seguimento de texto:

Por terem sido criados em famílias tradicionais e antigas, e em lugares afastados dos centros urbanos, não tendo muito acesso à informação, meus pais sempre foram um pouco fechados para certas coisas, especialmente meu pai, que tem uma maneira de pensar bem antiquada e conservadora.

Apesar dos seus temores e incerteza em relação ao futuro, no momento em que Ametista escreveu a sua autobiografia, pôde se posicionar e perceber o presente como um momento em que ela pode escolher livremente para constituir o seu ser-no-mundo de forma singular e diferente do seu passado, como diz Frankl (2011) a pessoa está em uma constante tensão entre o ser e o dever ser. Dessa forma, Ametista expressou em sua autobiografia uma atualização de um valor criativo que estava latente em seu passado:

Hoje em dia, tal fato faz mais sentido ainda para mim, uma vez que, depois de muito tempo, resolvi pintar um quadro novamente para uma atividade da faculdade. Nunca pensei que fosse algo que me faria tão bem, mesmo tendo aprendido a gostar muito de artes visuais. Pintar esse quadro depois de 8 anos desde a última vez foi libertador, como se eu tivesse me livrado de um peso e encontrado a mim mesma novamente.

A realização de um valor ou sentido sempre proporciona efeitos terapêuticos, nesse caso, um efeito libertador, reencontrar-se consigo mesmo poderia ser compreendido como reencontrar-se com a sua dimensão especificamente humana (noológica), a qual estava sendo bloqueada pela cotidianidade.

\section{Análise existencial da autobiografia de Topázio}

Topázio é um estudante universitário do sexo masculino, tem 24 anos de idade, em relação ao seu posicionamento religioso, ele se considera agnóstico com fortes tendências teístas. Além disso, descreve que viveu uma infância simples e feliz e se mostra bastante vinculado a sua família.

$\mathrm{Na}$ análise de Topázio a palavra que mais se repetiu foi a palavra "pai" e ela diz respeito aos seus pais, as suas experiências de vida com os pais e as referências que ele faz a estes. Já "vida" e "viver" referem-se a sua própria vida, suas experiências, seus valores, a forma como ele enxerga o mundo, sua cosmovisão. Assim como as duas palavras anteriores, a palavra "experiência”, como o próprio nome já diz, remete as suas experiências de vida. "Querer” está ligado, principalmente, com os desejos para o futuro. Por fim, "sentir" retrata seus próprios sentimentos.

A análise de similitude resultou em sete núcleos de sentido, os quais foram nomeados de: núcleo familiar; experiências ambivalentes; religiosidade; vivências; historicidade; vida profissional; vivência escolar. Os núcleos e suas ramificações podem ser observados na árvore de coocorrência na Figura 3.

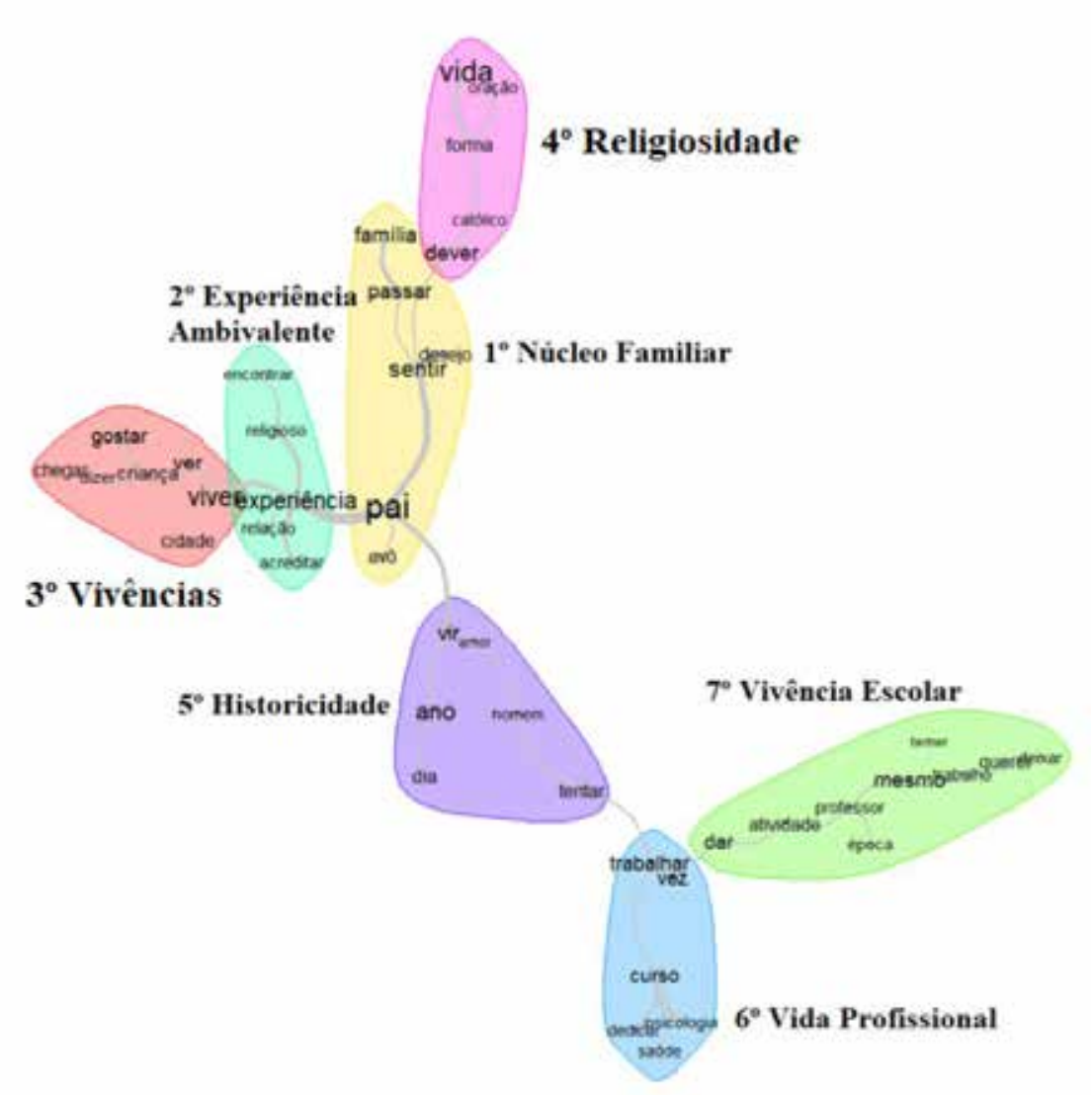

Figura 3. Árvore de coocorrência da autobiografia de Topázio 


\section{Núcleo familiar}

Este núcleo foi constituído pelas palavras: pai, avô, desejo, passar e família. Como por exemplo:

Também penso em homens mais próximos, como meu avô sanfoneiro e meu próprio pai, que por princípios morais fez-se um homem de não violência.

Nesse mesmo núcleo encontra-se referência a sua sexualidade:

Violência de lutar em vão contra os meus desejos, de me sentir diminuído e mal por algo que não tinha nada a ver com minhas escolhas ou muito menos com meu caráter; de tentar mudar minha sexualidade de forma artificial e por motivos que se deviam, em última instância, a crenças dogmáticas e não fatos objetivos.

Frankl (2011) descreveu os círculos viciosos que são reforçados por mecanismos de feedback. Provavelmente, no caso de Topázio, a luta contra o desejo reforçava o próprio desejo que gostaria de evitar resultando em uma frustração constante.

\section{Experiência ambivalente}

Nesse núcleo emergem as seguintes palavras: experiência, relação, acreditar, religioso e encontrar. Percebe-se que o núcleo familiar tem grande relação com o segundo - experiência ambivalente - pois, devido à vivência religiosa de seus pais e a sua na família, Topázio passou a ter comportamentos ambivalentes, que o levaram a dois caminhos: o da religião e o da pornografia. Além dessas ambivalências, este núcleo também diz respeito às vivências gerais de Topázio, ao que ele acredita e a relação dele com o mundo, com a natureza e com pessoas.

Curiosamente, os mecanismos que encontrei para lidar com isso foram opostos: a pornografia e o engajamento religioso ativo. Bem, eu disse que dois mundos existiam em mim... É óbvio que as duas coisas são de natureza absolutamente distinta, mas ambas me permitiam fugir de sentimentos que deveria ter enfrentado; hoje em dia, tenho procurado não cometer mais esse erro.

Ao considerar essa forma de ser no mundo como um "erro" ou como "oposto", emerge aqui a consciência valorativa (Gewissen), pois estabeleceu um julgamento acerca de sua escolha no seu ser passado, o que resulta em sua liberdade da vontade em se posicionar perante as futuras áreas do poderser. Por meio de valores de abertura e contemplação consegue dar sentido a sua experiência de ambivalência e dar um novo sentido ao seu vivido.

Acredito que vivi, ainda na infância, aquilo que Maslow chamava de 'flow', as experiências de pico, graças ao contato com a natureza.

Na sua compreensão, esse valor era congruente com a sua vivência religiosa:

Não havia, para mim, incongruência entre os valores que encontrava na causa ambiental e na minha experiência religiosa, na verdade via as duas quase como uma continuidade; entendia que assumir tal postura era também viver o evangelho.

\section{Vivências}

Este núcleo agrupou palavras como: viver, ver, cidade, criança, gostar, dizer e chegar. Está centrado nas vivências de Topázio, sejam aquelas que já estão eternizadas no passado, sejam as do presente ou as possibilidades contidas no futuro. Como exemplo, destaca-se a sua busca por uma religiosidade:

Mas me vejo distante da ortodoxia cristã e a forma específica como devo viver minha religiosidade ainda é um caminho por se descobrir.

Frankl (1990) argumenta que quando a tradição é rompida, o ser humano pode reencontrar sentidos na vida por meio de sua própria consciência valorativa (Gewissen). Neste caso, Topázio busca se distanciar de uma religiosidade inautêntica para satisfazer a sua vontade de sentido.

\section{Religiosidade}

Este núcleo reuniu as palavras: vida, oração, forma, católico e dever. Retratar a vida religiosa de Topázio, que antecipou o seu ser-no-mundo e que teve mudanças ao longo de sua vida, porém, mesmo com essas mudanças ele não deixou de buscar sua religiosidade, preservando um dos fenômenos genuinamente humano (Frankl, 2011).

(...) a escolha de meu nome e da forma como eu deveria ser educado baseou-se na busca por coerência com as experiências que haviam marcado tão positivamente a vida de meus pais dentro da Igreja Católica

Frankl (2019) alerta que tanto o conformismo, fazer o que os outros fazem, quanto o totalitarismo, fazer o que os outros querem, podem ser expressões de uma frustração da busca de sentido. No caso de Topázio, constata-se a sua luta interior para unir a sua vontade com o seu dever-ser, descoberto livremente e não imposto pela tradição.

\section{Historicidade}

Este núcleo reuniu as palavras: vir, amor, ano, dia, homem, tentar. Constata-se que este núcleo é composto por valores vivenciais e se constitui com uma autocompreensão positiva de sua biografia: 
Mas não me envergonho do homem que venho sendo até aqui, de minha história.

Topázio reconhece que a sua história de vida não o condiciona totalmente e manifesta novas posturas e intenções, como pode ser constatado no relato a seguir:

(...) quero orientar minha sexualidade para o amor e a realização de valores, sem negar meus desejos, mas sem me reduzir a uma busca pelo prazer.

A busca excessiva de prazer pode ser um sintoma de uma frustração existencial (Frankl, 2011). Nesse momento, Topázio revela a sua intenção em integrar a sua sexualidade por meio da dimensão do amor.

\section{Vivência escolar}

Este núcleo agrupou palavras como: dar atividade, professor, época, mesmo, trabalho, querer, temer. Neste ressaltam-se as experiências escolares de Topázio, como pode ser percebido a seguir.

Tive também, algum tempo depois, outra professora que fazia um trabalho muito simples de educação ambiental com as crianças do que hoje em dia creio que seria o primeiro ano fundamental

Esta lembrança parece ter sido significativa para Topázio, que manifesta em suas reminiscências experiências em sua biografia que deram sentido à sua vida. Esta compreensão corrobora o pensamento de Frankl (2017) para quem os valores do passado podem iluminar também a existência do momento presente, clarificando a sua busca existencial.

\section{Vida profissional}

Este núcleo foi composto pelas seguintes palavras: trabalhar, vez, dedicar, saúde. Abarca tanto o momento do presente quanto o futuro, após a conclusão do curso de graduação. Este núcleo se destaca pelo conteúdo acerca da vida profissional e revela a sua intencionalidade em se engajar em uma causa, conforme afirma:

Pretendo bradar aos quatro ventos em favor dos direitos humanos, do respeito à biodiversidade, $d a$ sustentabilidade ambiental e da seguridade social. Se preciso estou disposto a participar de passeatas, grupos organizados e a praticar a desobediência civil.
Na infância, Topázio relata a lembrança de aulas de educação ambiental, e momentos de contemplação da natureza em sua adolescência. São valores que emergem do passado e são atualizados como possibilidades de sentidos em sua área de liberdade do momento presente.

\section{Análise existencial da autobiografia de Quartzo}

Quartzo é um jovem do sexo masculino, com 23 anos de idade, evangélico e estudante universitário. Em sua autobiografia as palavras que mais se repetiram foram: querer, coisa, mãe, ano, vida e psicologia. A palavra 'querer' faz referência as vontades de Quartzo, o que ele almeja, seja na área profissional, seja em outras áreas. A palavra "psicologia” está relacionada com 'querer', principalmente por este ser o curso que ele almeja desde cedo. 'Coisa' foi uma palavra utilizada na construção da autobiografia para auxiliar na construção do texto, já ‘ano' e ‘vida' faz referência a historicidade e a própria vida de Quartzo.

Em sua autobiografia, a palavra que mais se repetiu foi “mãe”. Esta palavra faz referência a sua mãe e nos mostra a grande presença e importância que esta teve em sua vida. Com a análise de similitude foram encontrados oito núcleos de sentido denominados: Trabalho - valores criativos; superação; vontade; formação profissional; estudos; historicidade; vivências; cosmovisão. O núcleo e suas ramificações podem ser observados na árvore de coocorrência na Figura 4.

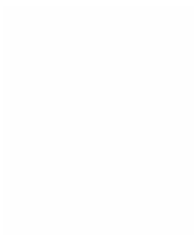

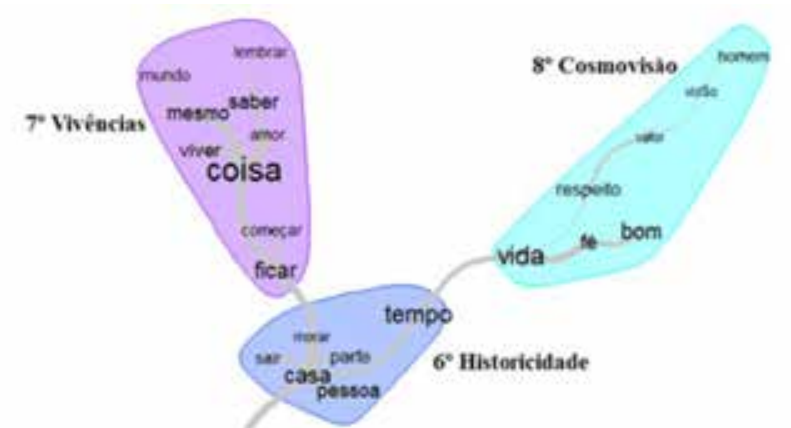

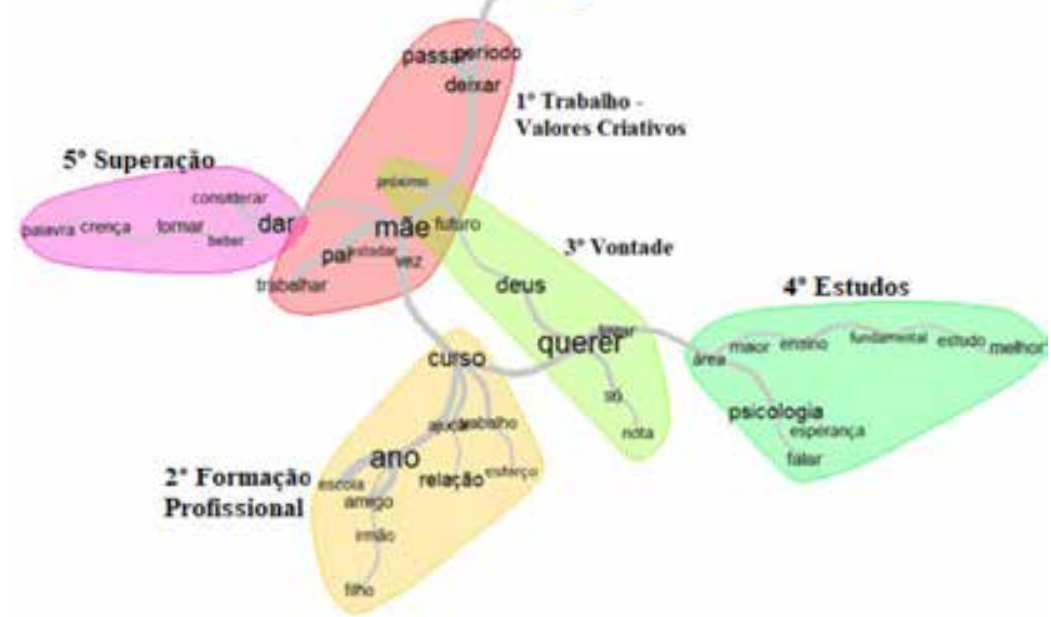

Figura 4. Arvore de coocorrência da autobiografia de Quartzo 


\section{Trabalho}

O núcleo de sentido foi composto pelas seguintes palavras: mãe, passar, período, deixar, paz, vez, estudar e trabalhar. Como exemplo, destaca-se a seguinte frase:

Minha mãe, trabalhando e estudando, fazia biblioteconomia à noite e me sustentava com um trabalho em eletrônica.

Possivelmente a mãe de Quartzo foi um modelo de abnegação e dedicação a sua família. Na compreensão de Frankl (1990), “(...) a vida só pode ser mais plena de sentido quanto mais difícil se torna" (p. 79), por outro lado, na sociedade de bemestar, o ser humano se encontra frustrado em sua busca de sentido. Dessa forma, a sua mãe foi uma fonte e modelo de dois valores que ele descobriu em sua própria existência: o trabalho e o estudo.

\section{Formação profissional}

Este núcleo de sentido foi formado pelas seguintes palavras: curso, ajuda, trabalho, esforço, relação, ano, escola, amigo, irmão e filho. A seguir um exemplo de um seguimento de texto deste núcleo.

Tenho a alegria de entrar no curso que sempre quis fazer.

Para Frankl (2011) o ser humano busca um fundamento ou um motivo para ser feliz, neste caso, Quartzo manifesta afetos positivos como consequência por estar realizando o seu projeto de vida.

\section{Vontade}

Este núcleo de sentido foi constituído pelas palavras: querer, Deus, futuro, só, nota. Como exemplo, destaca-se o seguinte trecho:

De alguma forma, me recordo dessa decisão ter sido tomada desde a época da infância, ainda no ensino fundamental. Tem menino que quer ser veterinário, jogador de futebol etc. Bem, eu sempre quis ser psicólogo.

A vontade requer um fundamento, um objeto para emergir no ser humano, neste caso o curso desperta a vontade de realizar este valor na sua existência.

\section{Estudos}

Este núcleo de sentido abarcou as seguintes palavras: área, psicologia, falar, maior, ensino, fundamental, estudo, melhor. Como exemplo, destaca-se a seguinte afirmação:

Meu ensino fundamental foi marcado por uma sensação de inferioridade, eu era o menor e sempre fui o menor. Mas o que não podia ser maior tinha que ser o melhor. Então eu tentava me dar bem nos estudos.

Frankl (1990) considera que, frente a um destino, ou uma situação imutável, o ser humano teria duas possibilidades, muda-lo quando possível, ou crescer interiormente, quando não é possível transformar a situação. Neste caso, como não podia mudar o ser biotipo, decidiu crescer intelectualmente, o que demonstra a capacidade humana em ser mais que a sua dimensão somática. Em outras palavras, quando o ser humano é confrontado com um destino inalterável, ele pode transformar um sofrimento em uma realização humana (Frankl, 2012).

\section{Superação}

Este núcleo de sentido foi composto pelas palavras: dar, considerar, beber, tomar, crenças e palavra. Destacam-se dois exemplos:

No ensino médio, as coisas ficaram mais graves, comecei a beber e a socializar com góticos, a gente até já invadiu um cemitério para beber lá dentro.

Este relato corrobora com o pensamento de Frankl (2011) quando concebe que na falta de tensões o ser humano procura compensações, seja criando tensões, seja consumindo álcool. Todavia, o ser humano pode transcender os seus condicionamentos, ou seja, "o homem é condicionado factualmente, incondicionado facultativamente" (Frankl, 2019, p. 166), conforme sugere o seguimento de texto a seguir:

Depois de alguns porres, vômitos e olhares de reprovação familiar, decidir parar de beber, e parei... a moral cristã me protegeu de muita coisa que derrubou bons amigos meus, como o envolvimento com facções e o tráfico.

Este núcleo retrata um possível vazio existencial vivido por Quartzo e este só é superado pela descoberta de um sentido por meio de sua religiosidade. Embora a realização de sentidos independe das crenças religiosas, Frankl (1990, p. 49) considera que "pode ser mais fácil ao homem religioso encontrar um sentido na vida (...)”. Frankl (2011) afirma que a descoberta de um sentido tem efeitos terapêuticos, pois capacita o ser humano a encontrar um "como viver".

\section{Historicidade}

Este núcleo de sentido foi composto pelas seguintes palavras: tempo, casa, pessoa, morar, parte e sair. Além disso, ele foi construído com base no conjunto de fatores que constituem a história de vida 
de Quartzo. Como exemplo observa-se a seguinte afirmação:

(...) e enquanto eu ia crescendo, ficava a maior parte do tempo com tios, avós, transitando entre casas de parentes.

A historicidade de Quartzo revela o seu ser passado como uma forma de existir. Entretanto, em nenhum momento apresenta autolamentação, sofrer por ter sofrido, o que sugere que esta reminiscência é percebida como um aspecto positivo de sua vida por não ter sucumbido a um destino trágico.

\section{Vivências}

Este núcleo de sentido foi composto pelas palavras: coisas, viver, amor, saber, mesmo, mundo, lembrar, começar e ficar. Como exemplo, ressalta-se a seguinte frase:

Pois como estava ficando cada vez mais complicado ficar na casa dos parentes, minha mãe me deixava numa escolinha dirigida por amigas suas.

Frankl (1989) compreende que o sofrimento ganha sentido no âmbito do sacrifício por algo ou alguém, em outras palavras, as dificuldades da vida configuram também um sentido na existência. Desta forma, quanto mais o ser humano se esforça para atingir uma meta, mais significativa é a sua realização (Frankl, 1989; 1990).

\section{Cosmovisão}

Este núcleo de sentido foi composto pelas palavras: vida, fé, bom, respeito, valor, visão e homem. A cosmovisão desvela a maneira pela qual Quartzo interpreta o mundo, que está vinculado a uma cosmovisão religiosa, como se revela a seguir:

E todos os meus esforços nessa vida que é fugaz como a relva, estão ligados ao meu desejo de ser um com Deus, na esperança de sua vinda, no cumprimento da sua vontade.

O relato acima sugere um relacionamento pessoal com um $\mathrm{Tu}$ transcendente, demonstrando uma vontade de sentido último. Para o homem religioso o sentido é encomendado por um contramestre (Frankl, 2010), identificado aqui como “a vontade de Deus". Por meio de sua fé em um supra Ser, Quartzo acautela-se do conformismo, fazer o que os outros fazem, típico em casos de frustrações existenciais (Frankl, 1989), conforme sugere o seguimento abaixo descrito.

As pessoas que não possuem uma fé cristalizada, podem realmente ser influenciadas a ponto de reconfigurarem sua vida de forma completa para serem aceitas em um grupo.
Frankl (1989; 2010) compreende que o homem não é condicionado pelo seu passado e muito menos pelos seus instintos. Dessa forma, Quartzo pôde fez escolhas livres motivadas por sua fé religiosa. Xausa (2003) aventa que apesar dos condicionamentos, sejam eles de ordem biológica, psicológica ou social, ainda há um ser livre e consciente, sendo dotado de uma 'vontade de sentido' (Frankl, 2011).

Também foi possível perceber a presença dos três valores na narrativa deste participante: os valores criativos aparecem por meio do trabalho e dos estudos, os vivenciais a partir de sua vivência com a família, namorada e amigos e os atitudinais aparecem pela sua mudança de atitude frente ao vácuo existencial pelo qual passou no ensino médio. Por fim, Quartzo e Ágata são os dois participantes que mais se aproximaram daquilo que Frankl (1989) chamou de Suprassentido (Übersinn): o sentido último da existência humana, que "ultrapassa a capacidade intelectual finita do ser humano" (Frankl, 2010, p. 142).

De forma geral, as autobiografias aqui analisadas, corroboram a visão da análise existencial proposta por Frankl (1989) de que vida é a fonte primária do sentido. Assim compreende o autor que "o sentido da vida é a própria vida" (Frankl, 2019, p. 291). Nesse caso, a palavra vida possui dois significados, no primeiro, possui o sentido de facticidade enquanto que o segundo ganha o significado de facultatividade. Nessa direção, podese compreender que o sentido na vida de hoje, o sentido do momento (facultativo), amanhã será o sentido da vida.

As análises das autobiografias possibilitaram apreender que a existência é experienciada como uma problemática especificamente humana (Frankl, 1989). Dessa forma, foi possível realizar uma análise existencial conforme sugere Viktor Frankl. Para o autor "(...) o sentido da vida é que o homem realize sua essência na existência" (Frankl, 2019, p. 292). A existência é constituída por possibilidades futuras e valores já sedimentados no passado, por conseguinte, o ser humano se constitui a partir do futuro, das possibilidades concretas que se encontram a disposição do ser para realizar a sua essência (Frankl, 2019), o que pode ser evidenciado por meio das histórias de vida aqui retratadas por meio da análise de similitude.

Considerando a premissa de que “(...) o autodesenvolvimento da existência pessoal sempre acontece por meio da autobiografia" (Frankl, 1991, p. 62), compreende-se que o sentido perpassa a temporalidade, posto que o tempo fluiria do futuro para o passado (Frankl, 2019). Já o presente se constituiria como a fronteira entre o ser e o não ser, onde "cada ato é o seu próprio monumento" (Frankl, 2019, p. 200). A autobiografia, por sua vez, poderia ampliar o campo perceptivo do fluxo do tempo, o que 
permitiria uma visada existencial do ser consciente e responsável na consecução da essência do ser que escolhe.

\section{Considerações finais}

Os objetivos desse artigo foram apreender valores existenciais e identificar núcleos de sentidos latentes em narrativas de vida de jovens universitários. Concebe-se que o seu escopo foi alcançado na medida em que foram encontrados núcleos de sentidos existenciais por meio da análise de similitude, que possibilitou apreender as configurações de sentidos latentes nas narrativas autobiográficas. Ademais, compreende-se que a metodologia adotada foi coerente com a Logoterapia e Análise Existencial, pois esta adota uma postura fenomenológica, pela qual a pessoa interpreta a própria existência no seu desdobramento na temporalidade (Aquino, 2013). Segundo as palavras do próprio Viktor Frankl "Em vez da negação niilista do sentido, deve-se buscar a interpretação do sentido. No entanto, 'interpretar' não significa dar um sentido qualquer, arbitrariamente à existência" (Frankl, 2019, p. 291). Dessa forma, a autobiografia poderia se constituir em um meio para encontrar o sentido concreto na existência.

Apenas de forma heurística, torna-se necessário diferenciar a logoterapia da análise existencial. Embora complementares, a análise existencial descreve o movimento do ser na temporalidade na busca do sentido na vida, contemplando tanto os valores na facticidade do passado quando na facultatividade das possibilidades futuras. Dessa forma, para uma finalidade terapêutica, a logoterapia se serve da análise existencial, conforme foi atestado por Viktor Frankl (1989), para a descoberta terapêutica do sentido na vida. Por esse motivo, o presente artigo não se deteve tão somente no sentido do momento, mas no sentido que permeia a historicidade presente, passada e futura.

Em contextos terapêuticos, recomenda-se esta metodologia da autobiografia para auxiliar na clarificação de sentidos na vida e também na compreensão ontológica dos pacientes, desvelando temáticas existenciais relevantes. Espera-se que futuros estudos possam ampliar a pesquisa com autobiografias para outras fases e idades, com o intuito de averiguar diferenças qualitativas na percepção dos sentidos na existência em função do ciclo da vida para compreender as estruturas existências que emergem com a temporalidade.

\section{Referências}

Abrahão, M. H. M. B. (2006). As narrativas de si ressignificadas pelo emprego do método autobiográfico Em: E. C. de Souza \& M. H. M. B. Abrahão (Orgs). Tempos, narrativas e ficções: a invenção de si. (pp. 149-170). Porto Alegre Salvador: EDIPUCRS \& EDUNEB.
Agostinho, S. (1981). Confissões. Porto, Livraria Apostólica da Imprensa. Originalmente publicado em 398.

Aquino, T. (2013). Logoterapia e análise existência: Uma introdução ao pensamento de Viktor Frankl. São Paulo: Paulus.

Becker, H. S. (1994) Métodos de pesquisa em ciências sociais. São Paulo: Editora HUCITEC.

Camargo, B. V., \& Justo, A. M. (2013). IRAMUTEQ: um software gratuito para análise de dados textuais. Temas em Psicologia, 21(2), 513-518. https://dx.doi.org/10.9788/TP2013.2-16

Bruzzone, D. (2011). Afinar la conciencia. Educación y búsqueda de sentido a partir de Viktor E. Frankl. Buenos Aires: San Pablo.

Bruzzone, D., (2018). Scrittura autobiografica e ricerca di senso: uno studio di caso, Ricerca di Senso, 2, 157-167. http:/hdl.handle.net/10807/123741

Frankl, V. E. (1989). Psicoterapia e sentido da vida: fundamentos da logoterapia e análise existencial. São Paulo: Quadrante.

Frankl, V. E. (1990). A questão do sentido em psicoterapia. Campinas, SP: Papirus.

Frankl, V. E. (1991). A psicoterapia na prática. Campinas, SP: Papirus.

Frankl, V. E. (2010). Em busca de sentido: Um psicólogo no campo de concentração. São Leopoldo: Sinodal, Petrópolis: Vozes.

Frankl, V. E. (2011). A vontade de sentido: Fundamentos e aplicações da Logoterapia. São Paulo: Paulus.

Frankl, V. E. (2012). Logoterapia e análise existencial: texto de seis décadas. Rio de Janeiro: Forense Universitária.

Frankl, V. E. (2017). Um Sentido Para a Vida: Psicoterapia e humanismo. São Paulo: Ideias \& Letras.

Frankl, V. E. (2019). O sofrimento humano: Fundamentos antropológicos da psicoterapia. São Paulo: É Realizações.

Kluckhohn, C., \& Murray, H. A. (1953). PersonalityFormation: The Determinants. In C. Kluckhohn, H. A. Murray, \& D. M. Schneider (Eds.), Personality in Nature, Society, and Culture (2nd ed., pp. 53-69). New York, NY: Alfred A. Knopf.

Lukas, E. (1998). Uma vida fascinante: Em la tensión entre ser y deber ser. Buenos Aires: San Pablo.

Oliveira, V. G. (2015). Olhar para existência com confiança. Revista Logos e Existência, 4, 36-44. 
Ovejas, P., Morelli, P. H., Moretti, M., Peña, B., Larrea, A. \&Eterovic (2013). La logoterapia em las villas. Buenos Aires: San Pablo.

Ratinaud, P. (2009). Iramuteq: Interface de $R$ pour les Analyses Multidimensionnelles de Textes et de Questionnaires [Computer software]. Recuperado de http://www.iramuteq.org

Ratinaud, P., \& Marchand, P. (2012). Application de la méthode ALCESTE à de "gros" corpus et stabilité des "mondes lexicaux": analyse du "CableGate” avec IraMuTeQ. In: Actes des 11eme Journées internationales d'Analyse statistique des Données Textuelles (pp. 835-844). Liège, Belgique. Recuperado de http://lexicometrica.univ-paris3.fr/jadt/jadt2012/Communications/Ratinaud,\%20Pierre\%20et20al.\%20-\%20 Application\%20de\%20la\%20methode\%20Alceste.pdf

Runyan, W. M. (1978). The life course as a theoretical orientation: Sequences of person-situation interaction. Journal of Personality, 46, 569-593. Disponível em: http://williamrunyan.com/article_content/life_course_theoretical_orientation.pdf

Thomas, W. I.; Znaniecki, F. (1927). The Polish Peasant in Europe and America. New York: Dover, $2^{\mathrm{a}}$ ed.

Xausa, I. A. M. (2003). O sentido dos sonhos na psicoterapia em Viktor Frankl. São Paulo: Casa do Psicólogo.

Amanda Karla Diniz Liberato Chaves: (https://orcid. org/0000-0001-8703-6118) Graduada em Psicologia (UFPB); Mestranda do Programa de Pós-Graduação em Ciências das Religiões da UFPB; Bolsista CAPES. E-mail: amandakarla.diniz@hotmail.com

Thiago Antonio Avellar de Aquino: (https://orcid. org/0000-0002-3903-8378) Departamento de Ciências das Religiões da Universidade Federal da Paraíba - Laboratório de pesquisa em Logoterapia e Análise Existencial (LAPLAE -CNPq). E-mail: logosvitae@hotmail.com

Recebido em 19.09.2019

Primeira Decisão Editorial em 29.07.2020

Aceito em 16.04.2021 